\title{
The Pandemic Hits Us Hard, but We don't Lose Hope
}

\author{
Krisna Yuarno Phatama ${ }^{1}$, Sholahuddin Rhatomy ${ }^{2,3}$, Asep Santoso ${ }^{4}$, Nicolaas C. Budhiparama ${ }^{3,5,6,7}$
}

\begin{abstract}
Department of Orthopaedics and Traumatology, Dr. Saiful Anwar General Hospital, Universitas Brawijaya, Malang, Indonesia
- Department of Orthopedics and Traumatology, Dr. Soeradji Tirtonegoro General Hospital, Klaten, Indonesia

Faculty of Medicine, Public Health, and Nursing, Universitas Gadjah Mada, Yogyakarta, Indonesia

- Department of Orthopaedics and Traumatology, Prof. Dr. R. Soeharso Orthopaedic Hospital, Universitas Sebelas Maret, Surakarta, Indonesia

- Nicolaas Institute of Constructive Orthopaedics Research and Education Foundation for Arthroplasty \& Sports Medicine, Medistra Hospital, Jakarta, Indonesia

5. Department of Orthopaedic Surgery, Leiden University Medical Center, Leiden, The Netherlands

Faculty of Vocational Studies, Universitas Airlangga, Surabaya, Indonesia
\end{abstract}

At the end of 2019, we faced a new variant of the coronavirus that can cause pneumonia and acute respiratory distress syndrome-like symptoms. It started in Wuhan, Hubei Province, China, and spread quickly to the whole world. This new virus is called Severe Acute Respiratory Syndrome Coronavirus 2 (SARS-CoV-2) and can manifest as a disease called coronavirus disease 2019 (COVID19). On March $13^{\text {th }}, 2020$ World Health Organization (WHO) declared COVID-19 as a global pandemic, and the story of frightening pancemic is begin $^{1,2}$.

\section{Hard hit by the pandemic}

The COVID-19 pandemic resulting from the severe acute respiratory syndrome coronavirus 2 (SARS-CoV-2) has radically transformed every aspect of daily life. Since the COVID-19 outbreak, many countries have reported decreasing numbers of hospital visits ${ }^{3}$. The Austrian, Chinese, Italian, and many other contries health centers report downward trends in the number of hospital visits, even in emergency cases ${ }^{4,5,6}$. Moreover, US centers have reported that emergency department visits dropped more than $50 \%$ during this pandemic ${ }^{7}$.

The impact that this new disease has given has affected many aspects of medical life, including the area of orthopaedic services. In order to alleviate the burden on the medical resources and ensure the safety of orthopaedic patients, surgeons, and other medical personnel, the American College of Surgeons (ACS) and American Academy of Orthopaedic Surgeons (AAOS) have recommended minimizing, postponing, or canceling all elective surgeries. Elective surgery is intended at patients with chronic diseases which by postponing the surgery will not cause any significant harm to the patients ${ }^{8,9}$. Although it is crucial to abide by this recommendation to help in preventing the spread of SARS-CoV-2, little is known about the impact of it on the patients, surgeons, and other areas.

Moreover, delays in surgery will have real impacts on patient health outcomes, hospital finances and resources, as well as training and research programs. A thoughtful and concerted effort is necessary to mitigate these effects. The SARS-CoV-2 (COVID-19) pandemic will leave a permanent mark on all aspects of society, including politics, culture, economics, health policy, and medicine. Hospitals are at the frontline of this crisis and have shifted their resources to handle the coronavirus pandemic on an unprecedented scale. No department has been left untouched from the effects of COVID-19, surgery included ${ }^{10}$.

The World Health Organization has warned against neglecting the provision of essential health services including surgical treatment ${ }^{11}$. Although personal protective equipment, medical equipment, and staff have been diverted to the current crisis, many patients with diseases which under normal circumstances would have been managed with elective surgical treatments, will go untreated as a result of the pandemic ${ }^{10}$. 
This crisis has placed unprecedented demands on resources leading to repurposing of surgical wards/ICU beds/ORs and relocation of anaesthesiologists, nurses and surgeons to help with workload of COVID-19 cases. This has resulted in complete stoppage of elective surgery in most countries ${ }^{12}$.

\section{The situation in Indonesia}

Actually, Indonesia is also hit quite hard. In the very beginning of pandeminc in the country, in March, the president signed the Government Regulation Number 21/2020 to exercise the largescale social restriction approach to control the spread of the disease. Non-essential activities were restricted, and only essential public places were allowed to remain open, such as grocery shops, gas stations, pharmacy shops, and hospitals. The measures undertaken in Indonesia were less rigid than those undertaken in China, the epicenter of the disease, where extreme measures were implemented, including a lockdown, except emergency medical cervices, of course $^{13}$.

Inline with other countries, Indonesian medical services have also been affected quite significantly, including in the field of orthopedics. Recently in November 2020, Sholahuddin Rhatomy, Krisna Yuarno Phatama, et al published the simple but essential study about the impact of the COVID-19 pandemic on orthopedic services in two Government's tertiary referral hospitals ${ }^{14}$. The study results can be valuable to health policy makers during this pandemic. The study evaluate the trend of orthopedic services, the monthly orthopedic surgical load and outpatient visits were examined during theperiod from March to May 2020 (the early pandemic period), in comparison with the same period in 2019 and analyzed separately. The result? As we predicted. They found a signifcant diference in the number of outpatient visits and orthopedic surgeries in the early pandemic period compared to the period before the pandemic occurred ${ }^{14}$. One thing is for sure, this frustating pandemic affects all of us in a significant way.

\section{A new hope: resuming elective surgeries}

Shortly after the World Health Organization declared COVID-19 a pandemic, the Centers for Disease Control and Prevention and the American College of Surgeons distributed guidelines on surgical resource management during the pandemic 15,16. Consequently, many hospitals ceased elective surgeries and procedures and significantly reduced the volume of operations that could be deferred with nonsurgical adjuvant options ${ }^{17}$.

As the virus becomes more prevalent, some outpatient surgery may be considered, pending availability of resources. Surgery for injuries such as anterior cruciate ligament tears, locked or bucket handle meniscus, acute traumatic rotator cuff tears, biceps injuries, and intra-articular displaced distal radius fractures (indeed, most fractures best managed by operative intervention such as femur or tibia fractures) should still be performed. If possible, these procedures should be done in the outpatient setting to minimize utilization of resources 9.

Another key recommendation has been published by The European Hip Society (EHS) and European Knee Associates (EKA) for planning to continue elective hip and knee arthroplasty during a new phase of the SARS-Cov-2 pandemic provide a framework to reduce the risk of a complete shutdown of elective surgery, as the preparation for the next COVID-19 wave ${ }^{18}$. Definitely, these recommendations boost optimism in resuming hipknee elective surgeries safely. Slow but sure, it seems that orthopaedic services including elective surgeries will be resumed as before the pandemic occured.

Anyway, We all know that this pandemic is very frustrating, makes most people despair, and almost give up. But, we should choose not to. We choose to fight this pandemic, adapt, and win this battle. We never lose our hope. 
"Difficulties and adversities viciously force all their might on us and cause us to fall apart, but they are necessary elements of individual growth and reveal our true potential. We have got to endure and overcome them, and move forward. Never lose hope. Storms make people stronger and never last forever." - Roy T. Bennett, The Light in the Heart

\section{REFERENCES}

1. Rothan HA, Byrareddy SN. The epidemiology and pathogenesis of coronavirus disease (COVID-19) outbreak. J Autoimmun. 2020;109:102433

2. Livingston $\mathrm{E}$, Bucher $\mathrm{K}$, Rekito A. Coronavirus Disease 2019 and Influenza 2019-2020. JAMA. 2020;323(12):1122./

3. Hartnett KP, Kite-Powell A, DeVies J, Coletta MA, Boehmer TK, Adjemian J, et al. Impact of the COVID-19 pandemic on emergency department visits United States, January 1, 2019-May 30, 2020. MMWR Morb Mortal Wkly Rep 2020;69(23):699-704. https://doi.org/10.15585/mmwr.mm6923e1

PMid:32525856

4. Lazzerini M, Barbi E, Apicella A, Marchetti F, Cardinale F, Trobia G. Delayed access or provision of care in Italy resulting from fear of COVID-19. Lancet Child Adolesc Health 2020;4(5):e10-1. https://doi.org/10.1016/s23524642(20)30108-5 PMid:32278365

5. Metzler B, Siostrzonek P, Binder RK, Bauer A, Reinstadler SJ. Decline of acute coronary syndrome admissions in Austria since the outbreak of COVID-19: the pandemic response causes cardiac collateral damage. Eur Heart J 2020;41(19):1852-3. https://doi.org/10.1093/eurheartj/ehaa314 PMid:32297932

6. Tam CF, Cheung KS, Lam S, Wong A, Yung A, Sze $M$, et al. Impact of coronavirus disease
2019 (COVID-19) outbreak on st-segment-elevation myocardial infarction care in Hong Kong, China. Circ Cardiovasc Qual Outcomes 2020;13(4):e006631.

https://doi.org/10.1161/circout-

comes.120.0066318.

7. Wong LE, Hawkins JE, Langness S, Murrell $\mathrm{KL}$, Iris $\mathrm{P}$, Sammann $\mathrm{A}$. Where are all the patients? Addressing Covid-19 Fear to Encourage Sick Patients to Seek Emergency Care. NEJM Catalyst Innovations in Care Delivery; 2020. p. 3.9.

8. American College of Surgeons. COVID-19: Recommendations for Management of Elective Surgical Procedures; 2020. Accessed May 25, $2020 . \quad$ https://www.facs.org/media/files/covid19/recommendation_for_elective_surgical_procedures.ashx

9. American Academy of Orthopaedic Surgeons. AAOS Guidelines for Elective Surgery - American Academy of Orthopaedic Surgeons. Published April 2, 2020. Accessed May 24, 2020. https:/www.aaos.org/about/covid-19-information-for-our-members/aaos-guidelines-forelective-surgery

10. Sue J. Fu, et al. The consequences of delaying elective surgery : surgical perspective. Ann Surg. 2020;272(2):e79-e80.

11. COVID-19: Operational guidance for maintaining essential health services during an outbreak. Available at: https://www.who.int/publications-detail/covid-19-operational-guidance-for-maintaining-essential-health-services-during-an-outbreak. Accessed April 2, 2020.

12. CovidSurg Collaborative, Nepogodiev D, Bhangu A (2020) Elective surgery cancellations due to the COVID-19 pandemic: global predictive modelling to inform surgical recovery plans. Br J Surg 12. 10.1002/bjs.11746 
13. Thornton J. Covid-19: A\&E visits in England fall by $25 \%$ in week after lockdown. BMJ 2020;369:m1401. https://doi.org/10.1136/bmj.m1401

PMid:32253175.

14. Sholahuddin Rhatomy, Krisna Yuarno Phatama, Faiz Alam Rasyid, Edi Mustamsir. Changes in orthopaedic services in two Indonesian tertiary-referral hospitals during the coronavirus-19 pandemic. Open Access Macedonian Journal of Medical Sciences. 2020;8(T1):538-41.

15. CMS adult elective surgery and procedures recommendations: limit all non-essential planned surgeries and procedures, including dental, Until Further Notice. https://www.cms.gov/files/document/31820cms-adult-elective-surgery-andproceduresrecommendations.pdf

16. COVID-19: guidance for triage of non-emergent surgical procedures. https://www.facs.org/covid-19/clinical-guidance/triage.

17. Oscar K Serrano, et al. Getting back to work: A framework and pivot plan to resume elective surgery and procedures after COVID-19. Surg Open Sci. 2020

18. Simon T Donell, Martin Thaler, Nicolaas C Budhiparama, et al. Preparation for the next COVID-19 wave: The European Hip Society and European Knee Associates recommendations. Knee. 2020;28:2747-55. 